\title{
Literatura na Hora Certa, um pacto para o letramento literário? Uma análise da proposta de formação do Pnaic
}

\section{Literature at the Right Time, a pact for the Literary Literacy? An analysis of the PNAIC training proposal}

\author{
Elza Rodrigues Barbosa Peixoto \\ Universidade Federal do Tocantins \\ Araguaína, Tocantins, Brasil
}

Maria José de Pinho Universidade Federal do Tocantins Palmas, Tocantins, Brasil

\begin{abstract}
Resumo: Este artigo discute e analisa discursivamente a ação de formação do professor alfabetizador, trazida pelo PNLD/PNAIC na edição 2015, através do Guia de Literatura na Hora Certa. Optou-se pela semiótica greimasiana como abordagem de análise dos discursos presentes nos guias sobre o processo de escolarização da leitura literária, com o objetivo de verificar se as concepções ideológicas que perpassam os discursos da referida ação de formação entram em conjunção com o que nos propõe os estudos do letramento literário e quais imagens de escolarização literária projetam em seu discurso. Evidenciou-se, pela análise empreendida, que, no percurso temático da literatura na alfabetização, marcar as séries iniciais como a hora certa da literatura foi o fio condutor da proposta-guia, reiterada nas diversas vozes que compuseram esse discurso.
\end{abstract}

Palavras-chave: Leitura, alfabetização, letramento literário.

\begin{abstract}
On this paper, we talk and analyze discursively the training action of the literacy worker, brought by the PNLD/PNAIC in the 2015 edition, through the Literature Guide at the Right Time. We opted for the Greimasian semiotic as an approach for analyzing the discourses present in the guides about the literary reading process of schooling. Insofar, we verified the ideological conceptions that go beyond the speeches of such training action and come in conjunction with what they proposed through the literary and literacy studies. Thus, observing which images of literary schooling project in your speech. It was evident, by the analysis undertaken, that in the thematic course of literature in literacy, checking the initial series as the right time of literature was the guiding principle of the proposal, reiterated in several voices that composed that speech.
\end{abstract}

Keywords: Reading, literacy, literary literacy

* Doutoranda do programa de Pós-graduação em Letras da Universidade Federal do Tocantins. Professora e coordenadora pedagógica. E-mail: elza.peixoto21@gmail.com.

** Professora Doutora, da Universidade Federal do Tocantins e do Programa de Pós-graduação em Letras e no Programa de Pós-Graduação em Educação. Membro da Rede Internacional de Escolas Criativas - RIEC. E-mail: mjpgon@uft.edu.br. 


\section{CONSIDERAÇÕES INICIAIS}

A proposição deste artigo se justifica e se organiza a partir de duas questões de base importantes de serem discutidas no atual cenário educacional brasileiro. Uma diz respeito ao papel da literatura em sala de aula na formação do leitor; a outra questão se refere à literatura na alfabetização. Essas questões estão ligadas, neste estudo, pelo Pacto Nacional de Alfabetização na Idade Certa (doravante PNAIC), edição 2015, em sua proposta de formação de professores, organizada no formato de guias, manuais que acompanham o acervo selecionado de literatura que é distribuído pelo governo federal às escolas cadastradas no referido programa.

Desse cruzamento de bases nascem as reflexões que aqui nos propusemos a fazer: Por quais rumos caminha a abordagem dada ao texto literário na formação do professor alfabetizador, dentro de um dos mais abrangentes programas de formação continuada, o Pacto? Quais concepções assumem no trabalho com a leitura literária no ciclo de alfabetização? A proposta apresentada no Guia Literatura na Hora Certa segue quais rotas, ancoradas em quais discursos?

Essas foram as indagações motivadoras deste trabalho, que tem como objetivo ampliar as reflexões sobre leitura literária na alfabetização, analisando discursivamente a ação de formação do professor trazida pelo Guia de Literatura na Hora Certa. Nosso foco é o tratamento dado ao texto literário na fase de alfabetização, que tem o guia como seu primeiro "caderno de formação" específico para professores das séries iniciais, lançado pelo PNLD/PNAIC, na edição 2015. A pertinência em trazer esse tema à discussão justifica-se, primeiro, por reconhecermos a alfabetização como um dos momentos cruciais nos processos de letramento; depois, porque parece que muitos professores têm se "esquecido" ou "deixado de lado" o verdadeiro potencial da literatura a ser explorado nessa fase de formação do pequeno leitor, "acomodados" a um modelo pragmático e utilitarista do texto literário como checagem de decodificação de leitura.

Nesse sentido, para cumprir os objetivos deste estudo, tomou-se como corpus de análise os volumes 1, 2 e 3 do Guia de Literatura na Hora Certa- 2015 (PNLD/PNAIC), correspondentes aos três anos iniciais do ensino fundamental. A escolha pela análise discursiva se deu em virtude da crença em uma necessidade primeira de verificar se as concepções ideológicas que perpassam os discursos da referida ação de formação entram em conjunção com o que nos propõe os estudos do letramento literário e quais representações de escolarização literária projetam em seu discurso. Para tanto, mobilizaremos a semiótica discursiva greimasiana, empreendendo a análise dos percursos temático-figurativos nos guias referenciados.

Embora a proposta de formação continuada do PNAIC tenha iniciado seu ciclo em 2013, com a formação em Língua Portuguesa, e mesmo tendo ações de aplicações imediatas, tanto os resultados como as análises das iniciativas do programa ainda estão longe de serem significativas. Apenas começam a despontar e apontar elementos que possam contribuir com o panorama geral do campo educacional brasileiro. Pesquisas acadêmicas e discussões em eventos científicos lançam algumas cores no quadro geral do programa, entre elas, alguns tons suaves de otimismo com resultados positivos já 
vislumbrados; outras, um tanto mais fortes na advertência pelos caminhos trilhados. Cabe pontuar que o olhar deste estudo está sempre com foco direcionado à abordagem dada ao texto literário, circunscrito ao âmbito da ação de formação docente do PNAIC, área com a qual desejamos contribuir com a relevância das reflexões e análises aqui empreendidas.

Para melhor circunscrever o objeto de estudo dentro do seu panorama geral, buscou-se, inicialmente, uma breve contextualização da formação em Língua Portuguesa do professor alfabetizador, a partir da abordagem teórico-metodológica trazida pelo PNAIC (2013), contando também com algumas incursões a estudos recentes que tratam da abordagem dada pelo Pacto à literatura, até a inserção, em 2015, do Guia de Literatura na Hora Certa, disponibilizado pelo Ministério da Educação e Secretaria de Educação Básica MEC/SEB, como "apoio pedagógico ao processo de introdução das crianças à cultura do escrito", distribuídos junto com os acervos especificamente selecionados para as salas de aula dos três anos iniciais do ensino fundamental pelo PNLD/PNAIC1.

Num segundo momento, empreendemos uma análise dos discursos presentes nos guias sobre o processo de escolarização da leitura literária numa abordagem semiótica; para, por fim, estabelecermos algumas reflexões sobre o papel da literatura em sala de aula e conexões entre as análises realizadas, tendo como suporte os discursos teóricos que tratam da "adequada" escolarização da leitura e literatura e o letramento literário.

\section{O LUGAR DA LITERATURA NO PACTO NACIONAL DE ALFABETIZAÇÃO NA IDADE CERTA}

O PNAIC foi instituído no ano de 2012 pelo Ministério da Educação (BRASIL, 2012a; 2012b; 2012c) e implementado por todo o país em 2013, por meio de acordo formal feito entre governo federal, estados, municípios e entidades, com o objetivo de alfabetizar todas as crianças até oito anos de idade. É composto sob quatro eixos de atuação: formação continuada de professores alfabetizadores; elaboração e distribuição de materiais didáticos e pedagógicos; avaliações e gestão, controle social e mobilização.

No eixo da formação, o objetivo proposto pelo programa tem visado, conforme exposto em seus documentos, a formação de educadores críticos, que proponham soluções criativas para os problemas enfrentados pelas crianças em processo de alfabetização. Esse item se completa no eixo de materiais didáticos, com obras literárias e de apoio pedagógico, além de jogos e tecnologias educacionais, numa junção de elementos que estruturam e dão suporte às formações oferecidas. Apresentado como referência o Decreto ${ }^{\circ}$ 6.094, de 24 de abril de 2007, a Portaria n867, de 4 de julho de 2012 e marca presença também na Meta 5 do Plano Nacional de Educação (PNE - Lei no 13.005/2014).

O PNAIC vem, juntamente com o Plano Nacional de Biblioteca Escolar - PNBE, ampliar o programa de distribuição de acervo literário. O diferencial é que seu acervo não se destina às bibliotecas, os kits do Acervo Complementar são de "uso coletivo em sala

${ }^{1}$ Esse material consta como compromisso formal do Ministério da Educação para o comprimento da meta 5 do PNE- Plano Nacional de Educação (2014-2020) e é parte do PNLD- Plano Nacional do Livro Didático do PNAIC. 
de aula". É importante destacar que somente as distribuições dos livros não sanam os problemas com a leitura, nem a presença simples do livro fará por si só a condução ou encantamento da leitura literária, constatação que coloca em evidência a figura do professor como peça fundamental, mas, para cumprir essa função, antes é preciso que seja um professor leitor.

Quanto mais evidente ficar para o professor a importância da leitura literária como poderosa fonte de formação de sensibilidades e de ampliação de nossa visão de mundo, que tem nessa linguagem artística um componente essencial de formação, culturalmente valorizado (embora pouco demandada e pouco ofertada socialmente), mais significativas se tornarão as práticas de letramento literário propostas. Isso tudo se, primeiro, o professor se conhecer como sujeito-leitor e souber dimensionar suas práticas de leitura, especialmente a literária. (PAIVA, 2008, p. 116).

Constatações como essa têm fomentado, nos últimos anos, ações que procuram dar sustentação ao ensino de forma mais consistente: muitos esforços em prol da adequada escolarização da literatura infantil, seja no nível das ideias, nas discussões do tema nos eventos literários e nos fóruns acadêmicos, seja nas políticas de distribuição de acervo literário para escolas públicas, PNBE, que se mobilizam para a existência e uso efetivo de bibliotecas escolares, entre outras iniciativas. Nunca se proclamou como agora a necessidade de formação de leitores que atendam às demandas do mundo contemporâneo. Os livros no espaço escolar são uma rica forma de acesso ao saber, mas como fica o professor, aquele a quem cabe ensinar a ler? A presença de um mediador preparado como leitor e como profissional é de suma importância para que a formação do pequeno leitor se efetive.

Ao longo das etapas de formação do PNAIC, a importância dada à formação do professor/leitor literário esteve marcada nos encontros de formação, sendo a literatura parte permanente de todo processo, como, por exemplo, a Leitura Deleite, atividade com a qual todos os encontros eram iniciados, colocada em prática a "[...] leitura de textos literários, com conversa sobre os textos lidos, incluindo algumas obras de literatura infantil, com o intuito de evidenciar a importância desse tipo de atividade" (BRASIL, 2012, p.32).

Korn e Koerner (2016) realizaram, recentemente, um estado da arte das produções científicas sobre o pacto Nacional da Alfabetização na Idade Certa entre 2013 e 2016. A investigação teve como lócus específicos as bases de dados da Coordenação de Aperfeiçoamento de Pessoal de Nível Superior (CAPES) e a Biblioteca Digital Brasileira de Teses e Dissertações (BDTD), na Associação Nacional de pós-graduação e Pesquisa em Educação (ANPEd), na Biblioteca Eletrônica Cientifica Online (SCIELO), nos Anais do XII Congresso Nacional de Educação (EDUCERE) e nos Anais da Associação Brasileira de Alfabetização (ABALF) cujo levantamento contribuiu como ponto de partida para nossa investigação por estudos que abordassem especificamente a leitura literária no PNAIC e que contemplassem alguma relação com a formação docente. Encontramos alguns trabalhos que apontam importantes reflexões sobre a abordagem dada à literatura na etapa de formação de Língua Portuguesa (2013). 
Importante observar que, dos estudos que se aproximaram da abordagem pretendida, um elemento comum figurou como destaque: a estratégia utilizada nos encontros de formação: a leitura deleite.

Souza (2016, p.9) em seu artigo discute sobre a leitura literária e a importância das políticas públicas na ampliação da compreensão leitora das crianças e apresenta como positiva a estratégia de formação do professor para as competências leitoras através da leitura deleite. Considerou essa estratégia, além de muito interessante, "um espaço para autonomia e autoria do professor e que favorece o respeito aos interesses e necessidades linguísticas e culturais dos alunos".

Domingues (2014, p. 125), em seu relato de experiência como formadora do PNAIC 2013, pontua que o programa "tem oportunizado aos professores uma experiência ímpar, pois a organização dessa formação está planejada para dar voz ao professor"; além disso, ressalta a importância dada à Literatura que constituiu "um diferencial" do programa, considerando as "possibilidades de potencializar a formação dos professores para a abordagem da literatura em sala de aula". Ainda registrando suas impressões, Domingues aponta que "o PNAIC veio para romper com uma realidade instituída nas escolas públicas de que a literatura não é significativa", ou não se tinha acesso a ela, ao menos a realidade do acervo estava transformada e a formação estava fazendo a outra parte: "As crianças leem mais, tanto para si quanto para a turma [...]" ressaltando o uso de textos literários com significado, encantamento e que garantem a possibilidade de um trabalho interdisciplinar (DOMINGUES, 2014, p.128).

Bazzo (2014a, 2014b) discute o tema em dois estudos e, embora avalie de forma positiva a formação literária do professor através das experiências compartilhadas e da leitura deleite, aponta para uma preocupação com os riscos ou as limitações que possam ser possibilitadas pelo reducionismo da simples reprodução das experiências relatadas nos Cadernos de formação do PNAIC, de 2013 e 2014, sem qualquer reflexão crítica.

Realmente, não há como se descartar os riscos apontados por Bazzo que são deveras significativos, tanto que o próprio caderno de formação traz como reflexão que "[...] a prática de sala de aula pode revelar e suscitar elementos que levam os professores a se verem em determinadas situações e a redirecionarem seus próprios gestos em outras situações semelhantes" (BRASIL, 2012, p. 13) e ainda propõe que, a partir dessa percepção, assumam com outro foco suas "responsabilidades" como "mediadores" de leitura e escrita, "mediadores entre a criança e o livro" (BRASIL, 2012, p. 13).

Fora o perigo da reprodução reducionista, ainda temos que considerar como desafiador o fato que a maioria dos professores alfabetizadores investem em sua missão de formação escolar do leitor literário, em sua maioria, sem formação literária suficiente. Temos que ter em mente que esse fato, por um lado, aumenta a importância de programa de formação em serviço com essa especificidade; e, por outro, a responsabilidade de encontrar uma metodologia que não privilegie modelos formatados, nem discursos reducionistas apresentados nas propostas, mas formar, ou ao menos fomentar, uma discussão da leitura literária significativa, que leve tanto alunos como professores ao letramento literário. Só para constar, o que aqui consideramos formação literária respaldamos em Paulino: 
A formação de um leitor literário significa a formação de um leitor que saiba escolher suas leituras, que aprecie construções e significações verbais de cunho artístico, que faça disso parte de seus fazeres e prazeres. Esse leitor tem de saber usar estratégias de leitura adequadas aos textos literários, aceitando o pacto ficcional proposto, com reconhecimento de marcas linguísticas de subjetividade, intertextualidade, interdiscursividade, recuperando a criação de linguagem (PAULINO, 2004, p.56).

É importante destacar que a formação do PNAIC para alfabetizadores não tinha a literatura como elemento direto de estudo até 2015, mesmo assim, como foi tratado anteriormente, através da "estratégia" da leitura deleite procurou marcar sua concepção de leitura literária como a leitura de fruição, demarcando um lugar de significativa importância no contexto de alfabetização e letramento.

Já em sua etapa mais recente, a perspectiva de um trabalho efetivo com o texto literário em sala de aula se tornou mais direto e sistematizado. Embora não tenha feito parte dos cadernos de formação ${ }^{2}$, que em 2015 estiveram centrados nas questões da interdisciplinaridade, a ação visou com uma só "caixa" realizar três "desejos": primeiro, ampliação de acervo literário para criar uma biblioteca fixa e acessível para as crianças e o professor dentro própria sala de aula; segundo, subsidiar, por meio de um guia de literatura, o saber-fazer do professor, com objetivo de potencializá-lo como mediador entre o livro e o pequeno leitor; e, por último, mas não menos importante, promover de modo "adequado" o processo de escolarização da literatura infantil, considerando a infância o melhor momento para favorecer o letramento literário das crianças.

De modo similar aos guias que compõem o $\mathrm{PNBE}^{3}$, o acervo distribuído foi dividido em três categorias: primeira: textos em verso - tais como quadra, parlenda, cantiga, trava-língua, poema, adivinha; segunda categoria: textos em prosa - tais como clássicos da literatura infantil, pequenas narrativas, textos de tradição popular, fábulas, lendas e mitos; e terceira categoria: livros ilustrados e/ou livros de imagens. Cada caixa de livros contém 35 títulos das três categorias. Os acervos são acompanhados dos Guias Literatura na Hora Certa: 1, 2 e 3, destinados à apresentação do processo de avaliação e

\footnotetext{
${ }^{2}$ A opção estratégica de não fazer parte dos cadernos de formação e sim participar como guia nas caixas de livros, segue a estratégia semelhante à realizada em 2014, na distribuição de livros do PNBE, com o PNBE NA ESCOLA Literatura fora da caixa - Guia 2, destinado aos anos iniciais do ensino fundamental. É claro que ainda não se pode mensurar se há ganho ou perda com essa estratégia, cabendo nessa linha uma outra investigação, visto que é um longo trajeto que esse material percorre até realmente chegar na escola, e, ainda assim, não se sabe os procedimentos realizados na recepção desses materiais pela escola, nem o tratamento dado ao guia, depois de aberta a caixa. Por outro lado, se fizesse parte dos cadernos de formação, haveria certa "garantia" que esse material seria discutido em encontros de formação, mas ficaria igualmente sem garantias de ser efetivado como linha de trabalho em sala de aula, posto que esse professor/destinatário precisa ser modalizado a crer nesse saber que está sendo posto para que ele realize sua performance. Todo material de formação do PNAIC está disponível no portal do Mec, incluindo os Guias de literatura na hora certa que são nosso objeto neste trabalho.

${ }^{3}$ Esses guias e os acervos distribuídos em parceria PNLD/PNAIC seguem na linha de ação formativa das publicações PNBE na escola: Literatura fora da caixa, organizados também em três volumes distribuídos com acervos para biblioteca, porém tendo como público a Educação Infantil, o Ensino Fundamental e a Educação de Jovens e Adultos (EJA).
} 
seleção das obras e ao apoio pedagógico no uso criativo das obras distribuídas no âmbito das ações do PNAIC.

Sobre essa nova ação do pacto, destacamos dois aspectos presentes nas discussões sobre o letramento literário: o primeiro diz respeito à importância da seleção das obras que, conforme destacado no texto de apresentação do guia, foi criteriosamente feita por especialistas a partir de sua qualidade textual, temática e gráfica, nas diversas categorias de textos literários. Outra questão é a promoção do encontro das crianças com o texto literário desde o início da alfabetização, tanto na "casa dos livros", a biblioteca, marcada pelo guia como espaço que se deve delinear desde cedo como "local de cultura e de conhecimento" capaz de, pela interação e acesso, levar ao hábito de frequentar a biblioteca ao longo da vida (BRASIL, 2015, p.12).

Da mesma forma, na sala de aula, nos "cantinhos da leitura" (ou outras formas que a criatividade dos professores produzir), contando com uma diversidade de gêneros literários sempre à mão "para que as crianças tenham liberdade para manipulá-los, folheálos, confrontar temas, gêneros, dimensões, número de páginas”; e que, da mesma maneira, o leitor-professor "possa ter ali, em sua sala, o livro que quer ler para as crianças, que quer discutir com as crianças, que quer usar para atividades de alfabetização e letramento" (BRASIL, 2015, p.14).

Nessa relação estreita com acervo de qualidade literária, trabalhando de forma lúdica e prazerosa com as crianças, demarca-se não apenas o lugar da literatura, como todo o cenário projetado pelo discurso da proposta, vislumbrando as possibilidades dessa ação e todo seu potencial para formar leitores desde pequenos. No entanto, para que isso aconteça, não se pode perder de vista que é fundamental a mediação do professor na introdução dessas crianças ao mundo da escrita, pela arte, pois, conforme salienta Aguiar (2006, p.254), "[...] através do caráter lúdico da literatura, o entendimento do leitor alastrase para além dos sentidos do texto", experiência que permite a compreensão do mundo em que vive, possibilitando a construção de seu próprio conhecimento.

\section{O GUIA DE LITERATURA NA HORA CERTA: UMA ANÁLISE DISCURSIVA}

No conjunto das investigações que, direta ou indiretamente, focalizam os fatos de linguagem, não são raras as tentativas de se compreender as maneiras como um dado grupo concebe um determinado tema ou assunto. A semiótica nos oferece para tal busca, dentre outros, recursos de grande utilidade para a análise e compreensão dos discursos, dos efeitos de sentido produzidos pela enunciação.

O corpus deste estudo é composto por uma coleção de orientações sobre literatura, correspondente às três séries iniciais do Ensino Fundamental, elaborada e distribuída pelo PNLD/PNAIC-2015 (volume 1, para $1^{\circ}$ ano - 2015a; volume 2, para $2^{\circ}$ ano -2015 b; volume 3, para $3^{\circ}$ ano - 2015c), intitulada Guia de Literatura na Hora Certa, destinada aos professores alfabetizadores.

Nessa investigação, como já citado anteriormente, mobilizaremos o nível discursivo da semiótica greimasiana. A semiótica francesa, considerada a teoria geral da significação, 
parte do pressuposto de que os textos possuem uma lógica geral subjacente. Isso equivale a dizer que há esquemas de organização comuns a todos os textos, independentemente das características que os individualizam. Considera que o sentido de qualquer texto é o resultado da reunião de dois planos: o de conteúdo e o de expressão, organizados (em sua forma standart) em um percurso gerativo de sentido, apresenta-se em três patamares que vão do mais simples ao mais complexo, divididos em: nível fundamental, nível narrativo e nível discursivo (Fiorin, 2009, p. 20).

O foco principal neste trabalho se pauta pelas relações do nível discursivo, de modo mais específico a perspectiva da semântica discursiva, na qual se observa o aspecto ideológico do discurso por meio de dois procedimentos essenciais: o arranjo de temas e figuras que é capaz de revelar os sentidos e valores históricos e socialmente partilhados pelos sujeitos.

Ressaltando que, de acordo com a organização do texto, a estruturação do enunciado será predominantemente figurativa ou predominantemente temática, dependendo de quais sejam os aspectos de "dominância", se abstratos ou concretos. Esses percursos, além de garantirem a coerência do texto, são os elementos de manifestação mais clara de intenções e proposições discursivas.

A análise dos guias mostrou o desenvolvimento do caráter intradiscursivo dos textos que se estabelecem amarrando grandes temas: o letramento literário, a escolarização da leitura literária e a mediação da leitura literária na alfabetização.

Em estruturação, os guias seguem um padrão, funcionando como recurso de apoio aos docentes em nível de progressão e aprofundamento, assim representado:

\begin{tabular}{|c|c|c|}
\hline Volume $1-1^{\circ}$ ano & Volume $2-2^{\circ}$ ano & Volume $3-3^{\circ}$ ano \\
\hline $\begin{array}{l}\text { Apres./Introdução ao } \\
\text { guia }\end{array}$ & $\begin{array}{l}\text { Apres./Introdução } \\
\text { guia }\end{array}$ & Apres./Introdução ao guia \\
\hline $\begin{array}{l}\text { A poesia no primeiro ano } \\
\text { do ensino fundamental }\end{array}$ & $\begin{array}{l}\text { A poesia no segundo ano } \\
\text { do ensino fundamental }\end{array}$ & $\begin{array}{l}\text { A poesia no terceiro ano do } \\
\text { ensino fundamental }\end{array}$ \\
\hline $\begin{array}{l}\text { Prosa para o pequeno } \\
\text { leitor }\end{array}$ & $\begin{array}{l}\text { Um dedo de prosa na sala } \\
\text { de aula }\end{array}$ & $\begin{array}{l}\text { Criança que aprende a ler fica } \\
\text { toda prosa! }\end{array}$ \\
\hline $\begin{array}{l}\text { Compartilhando } \\
\text { experiências com livros de } \\
\text { imagem }\end{array}$ & $\begin{array}{ll}\text { Imagens } & \text { narrativas } \\
\text { convidativas } & \text { a } \\
\text { de leitura } & \\
\end{array}$ & Ler imagens é ler o mundo \\
\hline $\begin{array}{l}\text { Quadrinhos } \\
\text { alfabetização: o caso do } \\
\text { Menino Maluquinho }\end{array}$ & XXXXXXX & $\begin{array}{l}\text { História em Quadrinhos na } \\
\text { alfabetização:Desconstruindo } \\
\text { um preconceito }\end{array}$ \\
\hline Obras selecionadas & Obras selecionadas & Obras selecionadas \\
\hline
\end{tabular}

Fonte: elaboração da pesquisadora

A partir do delineamento da 'estrutura composicional' dos cadernos do guia, foi possível identificar os percursos temáticos apresentados, seguindo na direção da leitura por categoria, ou seja, a abordagem da poesia em cada volume, depois a prosa e assim sucessivamente. 
Pela análise empreendida, verificamos que o discurso em questão é predominantemente temático e de figurativização esparsa. É o que acontece quando os discursos são mais abstratos, como esclarece Barros (2002). Os temas e as figuras são os modos de semiotização do mundo e exprimem, de acordo com Fiorin (2005b), as visões de mundo dos sujeitos, elementos que nos permitem vislumbrar as representações projetadas para a leitura literária no guia que se configuram como uma ação de formação de alfabetizadores.

No percurso temático da literatura na alfabetização, marcar o momento da alfabetização e letramento como a "hora certa para a literatura" é o fio condutor da proposta-guia que segue pelos volumes, alinhavando vozes que reiteram esse discurso.

Recortamos da introdução um fragmento que situa o propósito dessa ação:

[...] por que acervos de livros literários para cada uma das salas de aula dos três anos iniciais do ensino
fundamental?
Respondendo: porque é importante que os livros estejam cotidianamente ali, à vista e à mão, disponíveis
para professores (as) e crianças, nos três anos em que se introduz, se desenvolve e se consolida a
alfabetização, de modo que esta se faça sempre a partir da leitura e para chegar à leitura; a criança aprende
a ler para ler, e lê para aprender a ler - alfabetização e letramento, particularmente letramento literário.
(BRASIL, 2015, p.10 grifos da autora)

Essa sequência discursiva, organizada na forma de pergunta retórica, ilustra a estratégia argumentativa presente na introdução que abre todos os volumes e que vai se confirmando ao longo das reiterações temáticas nos capítulos. Esse excerto nos servirá para alguns apontamentos. O primeiro deles diz respeito à chamada de atenção, com grifos próprios, para a concepção de leitura como pontos de partida e chegada da alfabetização e letramento, incluindo o letramento literário. Concepção filiada à proposição de "alfabetizar letrando" de Magda Soares (2001, 2003).

Outro aspecto é a importância dada à materialidade dos livros para professor e alunos, "cotidianamente" "à vista e à mão", "disponíveis", especialmente dos 6 aos 8 anos, fase marcada discursiva e ideologicamente como a idade certa da alfabetização, automaticamente, hora certa para a literatura. Essa relação próxima entre a criança e o livro, agora tanto ao alcance da mão (PNLD/PNAIC 2015), nas salas de aula, como nas bibliotecas (PNBE), marca a relação da criança com o espaço social e individual de leitura, como recursos capazes de formar assíduos leitores para além da escola.

Essa proximidade da sala de aula, local de contatos que confere maior liberdade de manuseio para as crianças e para o professor, motiva ambos a construírem uma relação estésica com o livro, visto que, conforme Zilberman (2012, p. 149),

\footnotetext{
A Literatura infantil pode ajudar o professor a alcançar um resultado melhor, colaborando para o sucesso do seu trabalho. Os livros para crianças despertam o gosto pela leitura, não têm propósito pedagógico e ainda divertem. Os alunos certamente apreciarão acompanhar nas obras, as aventuras de personagens parecidas com eles, ação que os levará a buscar mais livros, solidificando sua competência leitora. A primeira medida a ser tomada pelo professor é, portanto, colocar os livros ao alcance dos alunos em sala de aula.
}

$\mathrm{Na}$ mesma linha, seguem os desdobramentos discursivos nos capítulos que tratam da poesia e da prosa nos anos iniciais, apontando a importância da "convivência com 
textos literários poéticos que exploram elementos lúdicos, tais como repetições e jogos de palavras, com forte apelo sonoro" como possibilidade de desenvolvimento do letramento literário, com uma especial orientação ao professor e referência ao papel imprescindível de exploração "adequada e planejada” de leitura compartilhada no $1^{\circ}$ ano.

Considera-se, assim, a atividade de leitura de livros para crianças na alfabetização inicial de suma importância, pois gera oportunidades para os alunos falarem sobre os textos a partir de uma experiência que mobiliza a sensibilidade e a afetividade. (p.20, vol.1)

Os acervos PNAIC que chegam às escolas oportunizam o cerne da experiência literária: oferecem fruição estética e, por meio dela, problematizações e oportunidades para imaginar e brincar, na direção do autoconhecimento e do conhecimento de mundo. (p.41, vol.1)

O discurso da literatura na hora certa é apresentado pelo guia com fundamentos em Bordini (1986, 2007), Lajolo (2001), Zilberman (2003), Soares (2003), Goldstein (2006), Cosson (2014), entre outros. Com argumentos de autoridade, suas concepções de leitura literária na alfabetização ganham em credibilidade pela chancela teórica de "especialistas" e são completadas na coerência das práticas propostas, demostrando que suas proposições práticas legitimam suas concepções teóricas, conferindo ao seu discurso legitimidade do saber.

É preciso ter em mente que, em situação de comunicação, há sempre um fazer de um sujeito destinador que constrói seu discurso no propósito de levar seu destinatário a crer nos valores apresentados, para conseguir que ele entre em conjunção com esses valores, aceite o contrato e passe a executar sua performance. Nesse caso, é necessário que o professor esteja convencido de que a alfabetização é a hora certa de se trabalhar com a leitura, sobretudo a literária, na perspectiva do letramento, que é a garantia de se fazer crer que "associar a leitura apenas à decodificação é uma redução" (p.37, vol.1) e que possa assumir seu importante papel nesse processo.

No percurso temático da poesia na alfabetização, destacam-se, nos três volumes, as fortes relações da infância com o brincar. Dessa forma, a poesia ganha status de "brinquedo inesgotável", “jogo com linguagem", um convite a brincar com as palavras, pois o "[...] caráter lúdico do texto poético propicia experiências com a linguagem em que a matéria-prima - a palavra oral e a palavra escrita - seja explorada, também ela, de modo criativo" (p.19, vol.1). Conforme avança a etapa, mais destaque confere à expressividade, num convite que o professor possa se envolver "com o jogo de sons e sentidos poéticos", "à brincadeira com os múltiplos sentidos", pois "a palavra tem um forte componente lúdico", (p.20, vol.2), conferindo ao professor a possibilidade de "interagir com poemas que exijam tanto a percepção de jogos de palavras e de sutilezas linguísticas que produzam efeitos de sentido, quanto o estabelecimento de relações entre os textos e o mundo" (p.19, vol.3).

Assim, introduzir o gênero com ludicidade, centrado na garantia certa de envolvimento da criança, estabelece o pressuposto de que é brincando com poesia e exercitando a percepção sobre os sentidos das palavras que se promove a ampliação dos significados do aprendizado da escrita.

Aprender a ler pelo contato com diferentes gêneros, incluindo o poético, oferece uma grande variedade de experiências com a linguagem, dada a sua inventividade. Assim, os elementos sonoros e rítmicos e 
o posicionamento estratégico de palavras ou expressões no texto possibilitam outras formas de leitura além da linear. (p.20, vol. 1 )

Nos capítulos que tratam da prosa, o jogo de sentido produzido pelo título dos volumes vai dando o tom do percurso temático das narrativas nas séries iniciais. Primeiramente, temos "Prosa para o pequeno leitor". Prosa, aqui, em duplo sentido: prosa - gênero narrativo, e prosa - oralidade, conversa, mais especificamente, contação de histórias, pondo em destaque a importante figura do professor como mediador de leitura nas contações de histórias, no encantamento e na interação criança-livro. Instigar a curiosidade da leitura autônoma já nessa fase é o destaque da orientação através da "exploração artística da prosa ilustrada", oferecendo "fruição estética" e assegurando "experiência imaginativa" (p. 41, vol.1).

$\mathrm{Na}$ continuidade, o segundo volume com o título "Um dedo de prosa na sala de aula", vem reforçando a importância de permitir ao leitor a leitura autônoma e destituída de outra intencionalidade pedagógica que não a própria oportunidade de "fruição literária na sala de aula", "do gosto pela leitura para o intercâmbio da cultura literária", oportunidade de "articular interesse da criança por livros de literatura às capacidades de leitura" e "os modos diferentes de interação e apropriação das obras" (p. 33-34 e 36, vol.2).

No último volume, a categoria da narrativa traz como título "Criança que aprende a ler fica toda prosa". O termo "toda prosa" nos remete tanto ao sentido de "toda faceira", alegre por ter aprendido a ler, como "bom de papo" pela ampliação de repertório que a leitura literária proporciona. Apresentam-se como palavras-chave: "arte, imaginação, atenção à linguagem literária e prazer" (p.37, vol.3, grifos dos autores) como forma de favorecer "a apropriação da leitura literária na escola", cabendo à escola ampliar esse contato das crianças com textos em prosa, instigando-as "a conhecer uma diversidade de textos cada vez maior, de modo que sua disposição para a leitura literária possa transpor os muros da escola" (p.38, vol.3).

Os pressupostos de leitura como fruição e potencial linguístico-cultural dessa modalidade está figurativamente representada na "semente da curiosidade" lançada pelas novas concepções de leitura literária, "plantada" no enunciatário e sob a qual o enunciador/destinador se coloca na torcida "para que ela encontre solo fértil nas escolas, de modo que cresçam e favoreçam um trabalho cada vez mais proveitoso com as obras que acabam de chegar via PNAIC” (p.51, vol.3).

Ressaltando a temática da mediação da leitura para o trabalho com os livros de imagens, o terceiro capítulo do guia fundamenta sua proposta como "um valioso recurso de aprendizagem" para todas as idades, não apenas para as crianças que ainda não sabem ler. Assim, destaca que a mediação "é fundamental para o exercício de um olhar mais sensível e inteligível”, é o meio para a ampliação da leitura e a percepção para uma apreciação do livro "que foge de uma leitura rápida e superficial e com ação autônoma do folhear", ou seja, é capaz de tornar a criança "um sujeito letrado visualmente" (p.59-60, vol.1).

A ilustração acompanha a literatura infantil de longa data, mas ganha espaço e incentivo desde 1981, quando a Fundação Nacional do Livro Infantil e Juvenil (FNLIJ) 
começou a premiar, anualmente, os melhores livros editados pertencentes à categoria "imagem". Desde então, o gênero livro de imagem ou livro ilustrado vem ganhando em notoriedade, qualidade artística e atraindo público, fator que recebe destaque no capítulo do guia a ele dedicado.

Os elementos temáticos que marcam o percurso da mediação de leitura estão centrados no "contato e no vínculo afetivo", dando destaque ao trabalho de apreciação desses livros, pois "as imagens são parte fundamental e integrante da estrutura do livro, contribuem para seu sentido, valor e narratividade" (p.50, vol. 2). Assim, o que vai conferir a potencialidade das "imagens narrativas como convidativas a exercícios de leitura" está intimamente ligado à condução dos mediadores na "leitura em voz alta e participativa", na "leitura coletiva", na "leitura afetiva", na "sensibilidade" (p.54, vol. 3). Enfim, o discurso centraliza-se nas possibilidades abertas com essa modalidade de leitura, à mão do professor e dos alunos, pois "Ler um livro de imagens estimula diversas competências visuais, cognitivas, simbólicas e reflexivas." (p.59, vol.1), contribuindo, inclusive, para a formação ou desenvolvimento do universo artístico do leitor e os modos de enunciar.

Ainda no percurso da mediação da leitura, na categoria dos HQs, a temática que marca o discurso é o "preconceito", ou melhor, o combate a ele. O enunciador busca quebrar a crença de que os quadrinhos servem apenas para "distrair a atenção dos estudantes", ou que podem ser lidos "apenas em momento de diversão", sendo por muitos apresentados apenas como "passatempo" (p.70, vol. 1). Busca desconstruir esse preconceito arraigado e marcar que HQs têm muito mais a oferecer à alfabetização e que podem ser um recurso pedagógico importante em sala de aula, sua integração de textos verbais e imagens, seus diversos recursos gráficos que vão conferindo a essas narrativas um "alto nível de informação" que "auxiliam no hábito" e o "caráter elíptico da linguagem dos Quadrinhos obriga o leitor a pensar e a imaginar, para completar os sentidos das histórias" (p.70-71, vol. 2).

Como última parada do guia, a apresentação visual dos acervos de todas as séries encerra arrematando um discurso que perpassa transversalmente os volumes e capítulos: a necessidade que "o professor se empenhe em ler o(s) acervo(s); se possível integralmente" (p.38, vol. 3) como forma de garantir que seja o mediador preparado, que o trabalho com a "adequada" escolarização da literatura prescinde.

\section{LITERATURA NA HORA CERTA, UM GUIA PARA O LETRAMENTO LITERÁRIO?}

Quando se fala em letramento literário, convém sempre refletir sobre sua relação de base com o letramento, ou sua vertente cada vez mais comum "letramentos". As diversas possibilidades adquiridas pelos sujeitos de participar de modo competente de práticas sociais também diversas. Então, poderíamos tratar o letramento literário, conforme Souza e Cosson (2011, p.102), como "demanda de um processo educativo específico que a mera prática de leitura de textos literários não consegue sozinha efetivar", posto que trata de um modo muito singular de construir sentidos pela linguagem literária. 


\section{Dessa forma,}

[...] é importante compreender que o letramento literário é bem mais do que uma habilidade pronta e acabada de ler textos literários, pois requer uma atualização permanente do leitor em relação ao universo literário. Também não é apenas um saber que se adquire sobre a literatura ou os textos literários, mas sim uma experiência de dar sentido ao mundo por meio de palavras que falam de palavras, transcendendo os limites de tempo e espaço. (COSSON, 2011, p.102).

Assim, a responsabilidade de sistematizar esse processo recai sobre a agência de letramento por excelência, a escola, e seu principal agente, o professor. Nesse sentido, em consonância com Soares (2001, p.47), é “inevitável” que se escolarize a literatura. Então, há a imprescindível necessidade de fazer o uso adequado do texto literário, respeitando sua função estética e evitando a postura de escolarização que "deturpa, falsifica, distorce a literatura", posturas que, muitas vezes, mais afastam que aproximam o aluno da leitura literária, ou que promovem nele "resistência ou aversão ao livro e ao ler".

Abordar o letramento literário, certamente, é parte integrante e relevante das discussões sobre o processo de escolarização da literatura. Nessa seara, Evangelista (2006, p.47-48) defende que a escolarização adequada é aquela que conduz "eficazmente às práticas de leitura literária que ocorrem no contexto social e às atitudes e valores próprios do ideal que se quer formar", cuja grande questão que está posta na relação escola e literatura é como realizá-la adequadamente. Sendo assim, o acesso a obras de qualidade já seria um passo, estabelecendo um contato, propiciando um vínculo como texto literário. (PAULINO; COSSON, 2009, p.74).

Nesse ponto, vale trazer à cena o discurso oficial de apresentação do guia, ao qual empreendemos análise, marcado por um desejo de que educadores "dedicados" aos processos de alfabetização e letramento "usufruam das obras selecionadas, com as crianças", com vistas ao "incentivo ao gosto literário, à imaginação, à ampliação das referências culturais e às formas - plurais e diversas - de leitura das palavras, das imagens e dos símbolos, por meio da leitura do mundo" (BRASIL, 2015, p.7).

Observamos que, em discurso, os propósitos se coadunam; no entanto, outra questão se apresenta: a necessidade de termos em salas de aula de todo o país "educadores dedicados", que sejam leitores e mediadores de leitura dos pequenos iniciantes, que realmente sejam leitores e usufruam dos livros com as crianças, pois, conforme Zilberman (2012, p.130),

O letramento literário se efetiva quando acontece o relacionamento entre um objeto material, o livro, e aquele universo ficcional, que se expressa por meio de gêneros específicos- a narrativa e a poesia, entre outros - a que o ser humano tem acesso graças a audição e à leitura.

Então, podemos considerar a proposta do guia como recurso formativo necessário ao letramento do professor alfabetizador, uma vez que

[...] o formador de leitor, dadas as diferentes circunstâncias, dentre elas as históricas, sociais, econômicas e culturais, se encontra fragilizado em seu conhecimento sobre o próprio objeto de ensino. E mais: muitas vezes domina muito pouco, ele próprio, as competências de leitura que pretende ensinar. (LEAL, 2006, p.263) 
O primeiro item a considerar no guia diz respeito à preocupação com a fundamentação teórica. Todos os capítulos metodológicos iniciam com reflexões sobre a formação do pequeno leitor, juntamente com fundamentos de teoria literária, conceitos (de letramento, leitura compartilhada, mediação etc.). Na sequência, apresentam exemplos de estratégias, dicas de como conduzir o processo de mediação de leitura, sempre respeitando o caráter das especificidades do gênero tratado, com sugestões de outras leituras para aprofundamento, finalizando cada capítulo com a bibliografia referenciada.

Os volumes do guia em questão são os únicos que chegam às salas de aula trazendo um conteúdo realmente formativo, de orientação e aplicação voltadas às necessidades específicas dos alunos em cada ano, de modo particular ao primeiro ano, com a importância do professor como mediador, não só "imputando" a ele essa responsabilidade, como o orientando no processo.

Conta também com chamadas de atenção sobre as atitudes do profissional, conforme se observa em alguns exemplos selecionados:

\footnotetext{
Professor, uma boa prática literária não ocorre por acaso. É preciso preparar com antecedência as atividades a serem exploradas: conhecer o livro a ser trabalhado, refletir sobre as possíveis intervenções didáticas a serem realizadas, considerando tanto o que o livro oferece como a realidade sociocultural dos alunos. (p.21, vol. 1, p.22, vol. 2 e p.23, vol.3)

Não realize um fechamento pedagógico de obras abertas.... Convide à fruição. Medeie a leitura atenta e as múltiplas interpretações. E, acima de tudo, não esqueça de se divertir com a turma! Além disso, de acordo com o perfil de cada turma, o trabalho proposto precisa ser modificado, e as provocações do próprio professor ao tomar contato com os livros podem fazer surgir excelentes ideias (ver, quanto a isso, Baldi (2009)). O importante é que você dê vida a esse acervo PNAIC: coloque-o, acima de tudo, a serviço das crianças. (p.52, vol. 1)
}

A abordagem que o guia traz para a poesia em sala de aula está centrada no lúdico, no jogo de palavras, ressaltando a potencialidade do desenvolvimento literário da criança através do forte apelo sonoro da poesia, elementos que favorecem o letramento literário das crianças. Propõe um trabalho pedagógico que favoreça a apropriação da leitura e escrita como algo significativo e relevante, gerando oportunidades que, na relação textoleitor, mobilizem a "sensibilidade e a afetividade", tomando como dinâmica sugestões que exploram o "Antes da leitura", o "Durante a leitura" e o "Após a leitura". Tudo isso muito bem explicado e valorizando não apenas o processo, mas os ganhos reais com o trabalho do gênero em sala de aula.

Nos capítulos das narrativas, tanto na Prosa, como no capítulo referente aos Livros de Imagens ou nas Histórias em Quadrinhos (HQs), o foco da progressão do trabalho na evolução das etapas escolares é constante. É possível perceber em cada abertura de capítulo uma reiteração de suas concepções de leitura literária, marcadas pelo caráter da fruição estética ou nas problematizações oportunizadas pelo imaginar e brincar como caminhos que conduzem na direção do autoconhecimento e do conhecimento de mundo. Tratam de forma pontual os perigos reducionistas da leitura como decodificação e do equívoco da utilização dos "textos como pretextos", defendendo a vinculação da alfabetização ao letramento e "vice-versa".

Os roteiros de práticas de leitura literária propostas nos guias se pautam, primeiramente, na organização de momentos de leitura como rotina escolar. Essas rotinas 
são divididas em dois momentos: a leitura autônoma e a leitura mediada. Considerando que as crianças do primeiro ano ainda não estão alfabetizadas, a alternativa à leitura autônoma, nessa etapa, é convertida em "escolha autônoma".

Apresentam a leitura autônoma como: “[...] momentos nos quais são privilegiadas as relações entre o leitor e seu livro, aquele que livremente tomou para ler; entre leitor e texto, aquele que, com sua história, este particular leitor fixou por sua singular leitura" (p.46, vol. 1). Sugere-se que esses momentos sejam organizados duas vezes na semana, um completamente autônomo e outro momento também autônomo, mas seguido de compartilhamento. Destaca, ainda, a importância de o professor considerar esse momento para observar as crianças em sua interação com o livro, como cada uma lê, conforme vão se tornando mais íntimos do livro, mais fluentes e experientes na leitura. Dois recados são bem marcados no guia: Um, "ao permitir que a criança circule pelos livros, estamos dando o recado de que a consideramos capaz de selecionar e de ler" (p.44, vol. 1). E o outro que a sensibilidade do professor para proporcionar esse momento é fundamental, a leitura em voz alta pelos alunos, as rodas de conversas sobre as leituras e sobre as escolhas, tudo são "oportunidades emergentes de ensino-aprendizagem."

Já na leitura mediada, sugere-se que seja uma vez por semana, pondo em evidência a importância da mediação na aprendizagem da leitura literária, o que justifica todo o cuidado com que são dadas as orientações e o detalhamento ao professor sobre cada etapa da mediação. As etapas seguem também as estratégias de "antes da leitura", "durante a leitura" e "depois da leitura", pautadas em Solé (1998), apresentadas nas práticas de trabalho escolhidas como exemplo de estratégia, incluindo orientações para o professor que deve não só assumir suas responsabilidades de leitor como atuar na mediação dos textos.

A postura evidenciada na proposta de leitura mediada do guia corrobora Paiva (2014, p.47) na importância dessa mediação que "[...] desenvolve nos alunos a vontade de expressão, a observação dos modos de contar uma história, assim como é uma atividade professor-aluno que cria vínculo e a vivência de experiências interlocutórias."

Dessa maneira, cabe ao professor estreitar os vínculos entre alunos e obras, buscando, gradativamente, as competências de ambos, o aprimoramento do processo de mediação que, efetivamente, participe e se comprometa com o processo de aprendizagem proporcionado pela literatura. Mesmo na fase de formação inicial do leitor, o professor deve considerar que ler é imergir num universo imaginário, gratuito, porém organizado, carregado de pistas as quais o leitor vai assumir o compromisso de seguir, se quiser levar sua leitura, isto é, seu jogo literário a termo (BORDINI; AGUIAR, 1993, p. 27).

\section{CONSIDERAÇÕES FINAIS}

Procuramos trazer à discussão, neste trabalho, a proposta de leitura literária na alfabetização produzida pela ação do Guia de Literatura na Hora Certa (PNLD/PNAIC 2015). Para perseguirmos nosso objetivo principal, que consistiu em explicitar certos processos de organização discursiva presentes nos três volumes que compõem os guias de orientação/formação do professor alfabetizador, buscamos identificar em quais 
concepções estão ancorados seus discursos, dando visibilidade às representações que projetam sobre o processo de escolarização da literatura na alfabetização.

Evidenciou-se, pela análise empreendida, que, no percurso temático da literatura na alfabetização, marcar as séries iniciais como a hora certa da literatura foi o fio condutor da proposta-guia, reiterada nas diversas vozes que compuseram esse discurso.

Do ponto de vista do processo de formação do professor alfabetizador para o trabalho com a literatura, consideramos uma evolução as abordagens dos guias em sua formatação gradativa, respeitando as fases das crianças e trazendo orientações específicas para cada categoria (versos, prosa, livro de imagens e HQs). Os guias se revelaram uma oportunidade ímpar de sanar a falta de uma formação específica ao docente alfabetizador, uma das causas da abordagem intuitiva da literatura em sala de aula ou, muitas vezes, apoiados no discurso do não saber fazer acabam por deixá-la de lado por considerá-la "difícil", ou ainda, em última instância, por observar apenas o caráter pragmático e utilitarista do texto literário como checagem de decodificação de leitura para o letramento literário.

Destacamos, nesse ponto, o jogo de cumplicidade proposto pelo enunciador. Nele, o caráter formativo se sobrepõe ao instrucional. As orientações oficiais propostas pelo guia para o trabalho com a literatura nas séries iniciais e reforçadas ao longo dos capítulos abordam a importância da materialidade dos livros "cotidianamente" "à vista e à mão" de professores e alunos, especialmente dos 6 aos 8 anos, fase marcada discursiva e ideologicamente como a idade certa da alfabetização, automaticamente, hora certa para a literatura.

Ao contrário do se vê em textos instrucionais ou em muitos manuais de orientação pedagógica, a dinâmica discursiva segue pelo envolvimento com o saber proposto, pela sedução e estabelecimento de cumplicidade. Sua abordagem não se reduz ao "cumprase", mas ao "porquê" de a literatura ser o melhor caminho e "o que" se pode ganhar no processo se se puser mais atenção e encantamento, no "como" mediar.

\section{REFERÊNCIAS}

BARROS, Diana Luz Pessoa de. Teoria Semiótica do Texto. 4 ed. São Paulo: Ática, 2002.

BORDINI, Maria da Glória; AGUIAR, Vera Teixeira de. Literatura - a formação do leitor: alternativas metodológicas. 2. ed. Porto Alegre: Mercado Aberto, 1993.

BRASIL. Secretaria de Educação Básica. Diretoria de Apoio à Gestão Educacional. Pacto nacional pela alfabetização na idade certa: currículo na alfabetização: concepções e princípios: ano 1: unidade 1/Ministério da Educação. Secretaria de Educação Básica, Diretoria de Apoio à Gestão Educacional. - Brasília: MEC, SEB, 2012.

. Literatura na hora certa: guia 1: $1^{\circ}$ ano do ensino fundamental: PLND/PNAIC Alfabetização na hora certa 2015 / Ministério da Educação, Secretaria de Educação Básica. Brasília: MEC/SEB,2015a. 
. Literatura na hora certa: guia 2: $2^{\circ}$ ano do ensino fundamental: PLND/PNAIC Alfabetização na hora certa 2015 / Ministério da Educação, Secretaria de Educação Básica. Brasília: MEC/SEB,2015b.

. Literatura na hora certa: guia 3: $3^{\circ}$ ano do ensino fundamental: PLND/PNAIC Alfabetização na hora certa 2015 / Ministério da Educação, Secretaria de Educação Básica. Brasília: MEC/SEB,2015c.

BAZZO, J. L. S. MUSA, M.L.N. Literatura infantil e juvenil na formação do professor alfabetizador: ou PNAIC na berlinda? Anais $6^{\circ}$ Seminário de Literatura Infantil e JuvenilSLIJ. Florianópolis: UFSC; UNISUL,2014a. P. 362-370.

BAZZO, J.L.S.; CHAGAS, L. M. M. Leitura de fruição no programa nacional de alfabetização na idade certa no Estado de Santa Catarina. Revista Linha Mestra, Campinas, SP, ano 8, n. 24, p. 144-162, jan./jul. 2014b.

DOMINGUES, Chirley. A hora e a vez da literatura infantil como parte significativa da formação do professor: experiências do PNAIC. In: Anais $6^{\circ}$ Seminário de Literatura Infantil e Juvenil-SLIJ. Florianópolis: UFSC; UNISUL,2014. p. 124-130.

EVANGELISTA, A. A. M.; BRANDÃO, H. M. B.; MACHADO, M. Z. V. Escolarização da leitura literária. 2. ed. Belo Horizonte: Autêntica, 2001.

FIORIN, José Luiz. Linguagem e ideologia. 5. ed. São Paulo: Ática, 1997. . Elementos de análise do discurso. 14. ed. São Paulo: Contexto, 2006.

LEAL, Leiva de Figueiredo Viana. Leitura e formação de professores. In: EVANGELISTA, Aracy Alves Martins et al. Escolarização da leitura literária. 2. ed. Belo Horizonte: Autêntica, 2001.

PAIVA, A. MACIEL, F. Discursos da paixão: a leitura literária no processo de formação do professor das séries iniciais. In.: PAIVA, A. et. al. Leituras literárias: discursos transitivos. 1 ed. $1^{a}$ reimpressão. Belo Horizonte: Ceale/Autêntica, 2008.

PAIVA, Ana Paula. Livros de imagem: Como aproveitar a atratividade e desenvolver o potencial dessas obras na sala de aula com atividades literárias. In: Centro de Alfabetização, Leitura e Escrita da UFMG (org.). PNBE na Escola: Literatura fora da caixa. Guia 1. Educação Infantil. Brasília: Ministério da Educação, Secretaria de Educação Básica, 2014. p. 45-60.

PAULINO, Graça; PINHEIRO, Marta Passos. Ler e entender: entre a alfabetização e o letramento. Revista Estudos, v. 2, n. 2. Belo Horizonte: Uni-BH, 2004.

. Algumas especificidades da leitura literária. In: PAIVA, Aparecida et al. (Orgs.). Leituras literárias: discursos transitivos. Belo Horizonte: Ceale; Autêntica, 2005. p. 55-70.

RESENDE, V.A.D.de R. Análises dos pressupostos de linguagem nos cadernos de formação em Língua Portuguesa do Pacto Nacional pela Alfabetização na Idade CertaPNAIC. 2015. 216 f. Tese (Doutorado em Educação) Unesp, São Paulo. 2015. 
SOARES, M. B. A escolarização da literatura infantil e juvenil. In: EVANGELISTA, A. A. M.; BRANDÃO, H. M. B.; MACHADO, M. Z. V. Escolarização da leitura literária.2. ed. Belo Horizonte: Autêntica, 2001.

SOUZA, Renata Junqueira; COSSON, Rildo. Letramento literário: uma proposta para sala de aula. Caderno de Formação: formação de professores, didática de conteúdos. São Paulo: Cultura Acadêmica, v. 2, p. 101-10, 2011.

SOUZA, R.J.; SILVA, K. A de A. M.; ARIOS, C. F. A Leitura e a Função da Literatura no PNAIC: para Além do Deleite. Educação em Revista: Marília, v.17, p. 63-80, 2016.

ZILBERMAN, Regina. A leitura e o ensino da literatura. Curitiba: InterSaberes, 2012. 